\title{
Framework for Investigating the Level of Compliance to the OHS Regulatory by the Small and Medium Construction Companies in Oman
}

\author{
Mubarak Al Alawi \\ alawim@squ.edu.om \\ College of Engineering, Sultan Qaboos University, Muscat, Oman \\ Mohamed Al Shahri \\ shahri@squ.edu.om \\ College of Engineering, Sultan Qaboos University, Muscat, Oman \\ Amjaad Al Ghafri \\ s117869@student.squ.edu.om \\ Tibudin \& Partners, Muscat, Oman
}

\begin{abstract}
The construction industry is characterized with a high rate of work-related accidents. Some of the accidents result in severe injuries and sometimes death. One of the reasons for such happenings is due to the noncompliance of the construction companies to the Occupational Health and Safety (OHS) regulatory framework. This paper briefly describes the preliminary results of the first part of an ongoing study. The study is composed of three parts studying the OHS practices in small and medium construction companies in Oman. The three parts are (1) identifying the level of compliance of the small and medium construction companies to the OHS regulatory framework, (2) comprehensively identifying the causation of the non-compliance and the risk generated, and (3) proposing a framework for "Paving Zero Accident Vision" in Oman. Oman's OHS regulatory framework was used to construct an evaluation survey. Sixty small and medium construction companies from two different governorates, Muscat and South Al Batinah, were involved in the study. Three evaluation results related to the construction site fencing, the nature of the project site, and the level of compliance to providing personal protective equipment were reported. The results showed that the $75.5 \%$ on an average, the construction companies fenced their construction site; for $59 \%$ on average the project site is a construction and an accommodation site at the same time, and the level of compliance to providing Personal Protective Equipment (PPE) is varying in both locations. However, both locations showed similar results in providing ear protection, eye protection, and safety shoes.
\end{abstract}

Keywords: OHS; Construction industry; Small and medium construction companies

\section{INTRODUCTION}

The construction industry is characterized with a high rate of work-related accidents that create unpleasant working environment; this statement has been frequently used in Occupational Health and Safety Research, and it has been the driving force in the development of new approaches, techniques to improve the OHS practices in the construction industry. However, leading the way to create a safe working environment is a joint effort between (1) the individual worker, (2) the employing company, (3) the 
client, (4) the relevant regulatory, governmental bodies, and (5) the international OHS agencies. Working in harmony and in an integrated way between relevant OHS parties is the key principal to pave the way to Zero Accident Vision (ZAV).

The behavior of the individual construction worker is the performance indicator of how effectively the employing company is managing its designated safety program. In addition, the rate of the construction-related accidents is normally used as an indicator by the relevant OHS regulatory governmental bodies on what degree the company is complying with the OHS regulatory framework. Also, the OHS regulatory frameworks are normally adopted by international OHS agencies. This sequential flow of about OHS facts chain, according to the author's perception, exist globally. Furthermore, it is contained within what is called the Safety Climate; safety climate is "the shared perception of values, beliefs, and procedures related to organizational safety" (He et al., 2020). The existence and the level of compliance to the OHS regulatory framework can be considered as the common chain, and therefore knowing to what degree the construction companies are complying with the OHS regulatory framework can help to identify the gaps and challenges the construction industry needs to bridge.

The level of compliance of the construction companies to the OHS regulatory framework differs in terms of the size (Legg et al., 2015). For example, large companies are better managing the OHS safety requirement than the small companies because large companies normally dedicate resources to apply more systematic approaches to health and safety (Hasle et al., 2009). On the other side, it is difficult and expensive for the small and medium companies to cope with the large companies' performance on maintaining a high level of OHS compliance, and they frequently focus their resources on surviving (Lai et al., 2011). This fact hinders spreading the awareness about the prime responsibility of the company, no matter what its size is, which is to maintain the legal requirement of the OHS. Thus, accident in the small and medium companies burden the major work-related accidents rate (Cagno et al., 2013).

It is worth mentioning that non-complying with the OHS regulation is associated with costs, which are the costs that arise from the occurrence of accidents. The cost is classified to tangible and nontangible, and its level of effect extends from the worker going through the family and friends, employer, and finally, the society (Ikpe et al., 2012). The nontangible cost related to society is the reduction of the human potential, and reduction of the quality of life. This kind of cost is not only non-bearable to society but also to the economy, causing imbalanced distribution of local human workers in the construction industry and rebel best talent. Hence, the well-being of the construction industry in general and the well-being of the small and medium construction companies, in particular, is essential.

Therefore, this research aims to investigate the level of compliance of the small and medium construction companies in the context of Oman's construction industry to Oman's OHS regulatory framework. It discusses research plan for ongoing research on studying the small and medium construction companies OHS practices, identifying the causations of not complying with OHS standards, and formulating "Paving the way to Zero Accident Vision" research direction in the future. 


\section{BACKGROUND}

Occupational health and safety for workers has been a vital and crucial factor at all levels of different organizations since the industry revolution (LaDou, 2003). The topic of health and safety compliance to local or global standards has received great attention in past decades. A comprehensive review by Salguero-Caparros et al. (Lai et al., 2011) to address the issues associated with compliance of implementing health and safety regulations. The paper reviewed the published studies that have investigated the interaction between OHS and compliance with legislation, regulation, and rules. Cagno et al. (2013) provided a constructive review of the past decade scientific work that dealt with economic evaluation of OHS. The features of modelling approaches and tools to assess the economic evaluation on small and medium companies were examined and methodological limitations were highlighted as well.

Gunduz and Laitinen (2017) proposed a ten-step occupational health and safety management system (OHS MS) framework for small and medium-sized construction companies to boost the level of OHS. Their study cantered on the small and medium companies within construction industry where most of the accidents occurred. OHSMS frameworks with different steps have been studied and proposed (Zhou et al., 2015) (Zhou et al., 2013). Other studies investigate the influences of adopting human resources skills and their effect on the health and safety outcomes (Lai et al., 2011) (Sunindijo $\&$ Zou, 2013). These studies identified and discussed research gaps and corresponding agenda, which can serve as guidance to factors that needed to be considered in future construction safety research and analysis.

The effect of health and safety management within small and medium enterprises have received a lot of attention in the developed countries. However, little attention has been invested in the developing countries. A study by Kheni et al. (2010) was conducted to fill that gap. The research aimed to study the influence of OHS within Ghanaian construction industry. More specifically, the study focused on small and medium construction enterprises to explore the practices and problems that render the effectiveness of implantation OHS standards. The study concluded that effective institutional structure and better socioeconomic environment among other factors are essential in order for better OHS practices within small and medium enterprises. Unnikrishnan et al. (2015) conducted a questionnaire survey to a number of 30 SMEs in India to measure the execution of safety practices within SMEs. The study, also, extended to investigate the obstacles and drivers for implementations of OHS practices. The study found that market competitiveness, better efficiency and rigid laws were among the main drivers for OHS implementation; whereas fiscal constraints, lack of knowledge and training were among the main barriers.

A study by Arewa and Farrel (2012) highlights the compliance of health and safety regulations within SMEs in United Kingdom. Since, the SMEs form around $90 \%$ of construction companies and since the OHS regulations are enforced in UK to all enterprises regardless of their nature or size. Therefore, health and safety incidents are more determinately in SMEs compared to the risk that might affect larger enterprises, which increases the financial uncertainties and risks in SMEs. The study emphasized on the relationship between the compliance of health and safety regulations and the financial performances within SMEs. The comprehension of the practitioners within UK 
organizations on the anticipated benefits of implementing health and safety standards was also investigated by Chileshe \& Dzisi (2012). Health and safety index was proposed to indicate the level of benefits from health and safety implementation and management within the construction industry.

\section{METHODOLOGY}

This research is conducted in three stages, shown in Figure 1,(1) identifying the level of compliance of the small and medium construction companies to the OHS regulatory framework, (2) comprehensively identifying the causation of the non-compliance and the risk generated, and (3) proposing a framework for "Paving Zero Accident Vision" in Oman. In this section, all of the stages will be briefly explained to show the methodology adopted in this research.

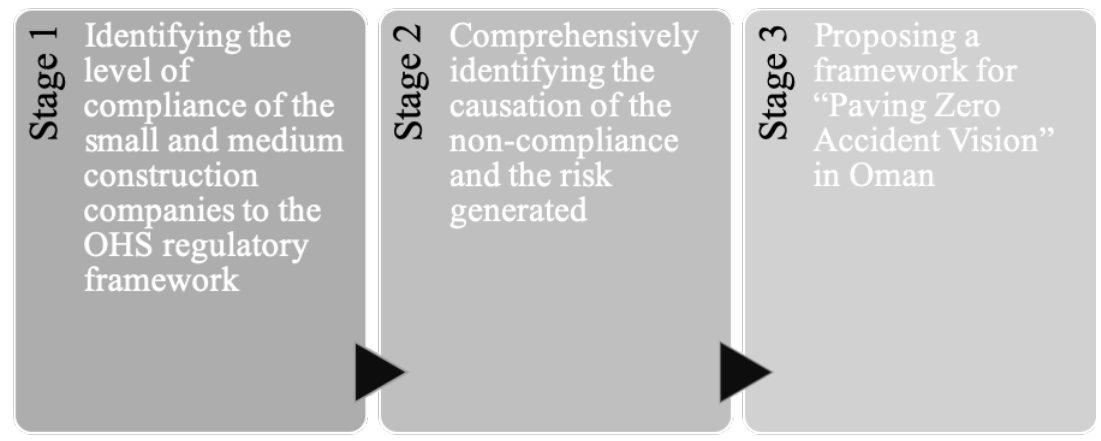

Figure 1: Research Work Sequence

\subsection{Identifying the level of compliance of the small and medium construction companies to the OHS regulatory framework}

To identify the level of compliance of the small and medium construction companies, first, the OHS regulatory framework adopted in Oman must be studied and used as a benchmark for the evaluation process. The Occupational Health and Safety regulatory framework was released as part of the Labor Law, which was promulgated by the royal decree No.35/2003. The OHS general guidance was published in part six under the title "Industrial Safety". The detailed description of the OHS regulatory framework can be found in the Ministerial Decision 286/2008 of the minister of Manpower (Ministry of Manpower, 2008). The OHS regulatory framework describes the following:

1. Definitions and General Provisions

2. General provisions

3. General Arrangements

4. Utilities

5. Specifications of Work Uniform and Personal Protection Equipment

6. Medical Care

7. Health Friendly Workplaces

8. Protection of women

9. Protection of the Disabled

10. Precautions Against Hazards 
The OHS regulatory framework was used to construct a checklist form, and not all ten parts were included rather only the "General Arrangement", "Utilities", "Specifications of Work Uniform and Personal Protection Equipment", "Medical Care", and "Precaution Against Hazards" were adopted. The selection of those parts was because small and medium construction companies are involved in building small to medium construction projects and this research targets only small and medium residential and commercial projects. The checklist form was distributed to 60 small and medium construction companies in two governorates in Oman, Muscat and South Al Batinah (the location is marked by symbol star in Figure 2). The expected results from this stage will not only pinpoint the level of compliance but also it will provide some valuable sight on the safety culture adopted by the companies.

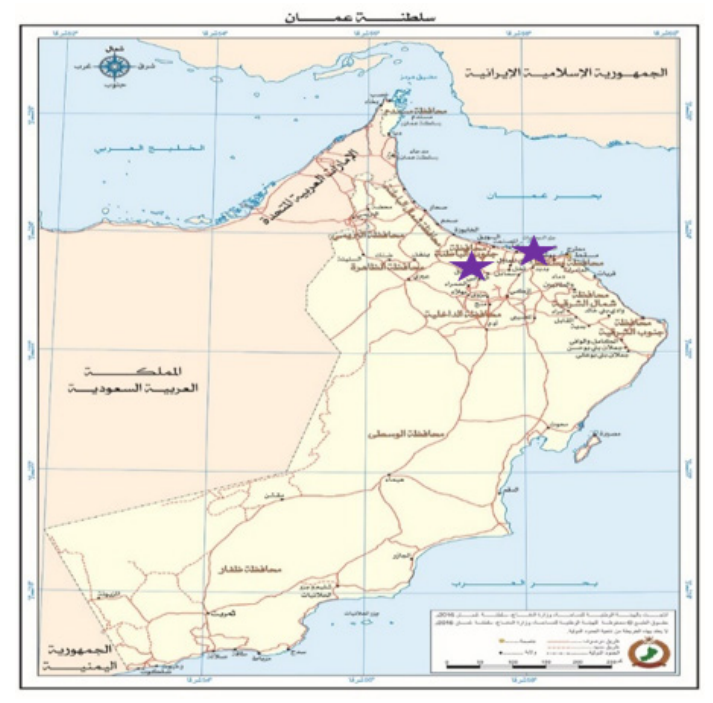

Figure 2: Locations of the Study in Oman (National Survey Authority, Ministry of Defence, 2019)

\subsection{Comprehensively identifying the causation of the non-compliance and the risk generated}

In this stage of the research, identifying the causation of the non-compliance and the risk generated is the main target. This stage aims to identify what factors cause the low level of compliance or implementation in the small and medium construction companies in Oman. This includes, but not limited, investigating the small and medium construction companies' awareness and understanding of the Occupational Health and Safety in Oman. This stage also aims to investigate ways to mitigate the factors affecting the level of compliance of the OHS regulatory framework.

\subsection{Proposing a framework for "Paving Zero Accident Vision" in Oman}

At the stage, paving the way to "Zero Accident Vision" will be proposed. A framework on how to move forward in marinating safe and healthy environment will be constructed. At this stage, expert engineers in the area of OHS will play a critical role in setting up 
the framework. A panel of experts from different companies representing a variety of industrial sectors will be formed, and rounds of discussion will be arranged to reach consistent agreements on how best to achieve the designated target.

\section{DISCUSSION OF RESULTS}

This section discusses only partial preliminary results of the first stage of the research. The small and medium enterprises are those having a number of resources less than 200 (Kheni, Gibb \& Dainty, 2010). The construction companies in Oman are also categorized according to their capital. There are five categories, Excellent ( $+250,000$ OMR), First (100,000-249,000 OMR), Second (50,000-99,000 OMR), Third (25,000-49,000 OMR), and Fourth (3,000-24,000 OMR) (Ithraa, 2015). The number and the classification of the construction companies involved in the study are shown in Figure 3. The number of small and medium construction companies that participated in the study from Muscat and South Al Batinah governorates is 24 and 36 respectively. Figure 3 shows that the majority of companies in Muscat are under the Excellent class Category; meanwhile, the majority of companies in South Al Batinah are under the First and Fourth class category.

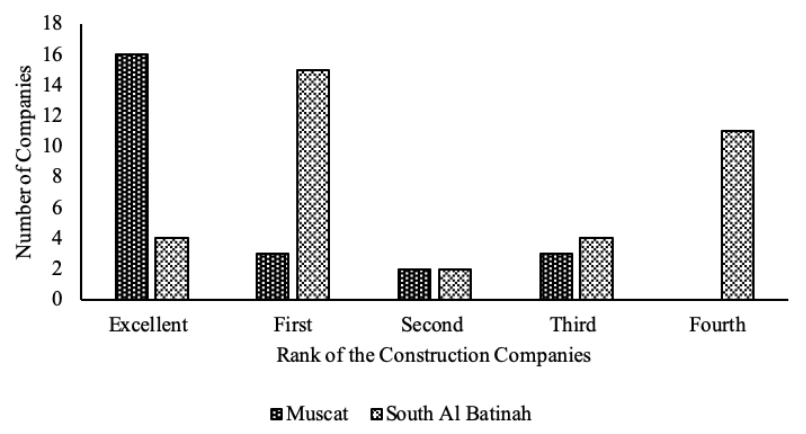

Figure 3: The Number of Construction Companies Studied in Each Class

Figure 4 shows the percentage of construction companies surrounding their construction site with a fence. Although, it is obvious that enclosing the construction site with fence is mandatory in all construction projects and it is one of the conditions which must be maintained to get a construction work permit, however, Figure 4 shows that not all companies are fencing their construction site; only $79 \%$ of the construction companies in Muscat and $72 \%$ in South Al Batinah have their construction site enclosed with fence. This act creates a new source for hazards to the society where the surrounding neighborhood is exposed to construction hazards. A report in 2015 published by the Muscat Daily with the title "Allegations arise that many construction sites in Muscat are giving safety a miss" highlighted this fact; some big machinery were lying around the construction site and causing serious threat to the residents (Muscat Daily, 2015). This observation raises a question on how the engineering office responsible in managing the project is monitoring and controlling the construction site; answering the question will help to identify one of the root causes of non-compliance to the OHS regulatory framework. 


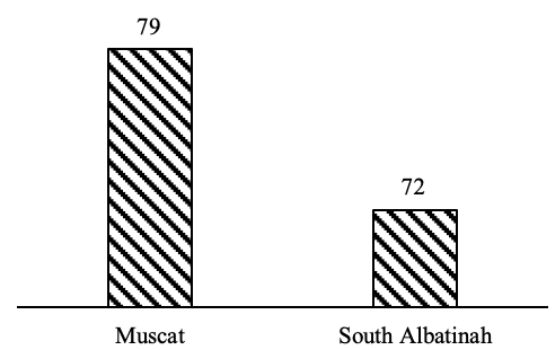

Figure 4: The Percentage of Construction Companies Surrounding their Construction Site with Fence

Figure 5 shows the results regarding the nature of the construction site, whether it is a construction site only or it is both, a construction and an accommodation site. Normally the workers' accommodation is separated from the construction site, and if not, the construction site must maintain certain conditions found in the General Arrangement, Utilities, and Health Friendly Workplace explained in the OHS regulatory framework. It was found that the majority of the construction companies had their construction workers accommodated in the construction site. This observation hints on how the small and medium construction companies are maintaining a healthy workplace. It is worth mentioning that part of the evaluation checklist thoroughly investigates the condition of the accommodation site and on what level it is complying with the OHS regulations. The answer is to be provided on a later stage of this research.

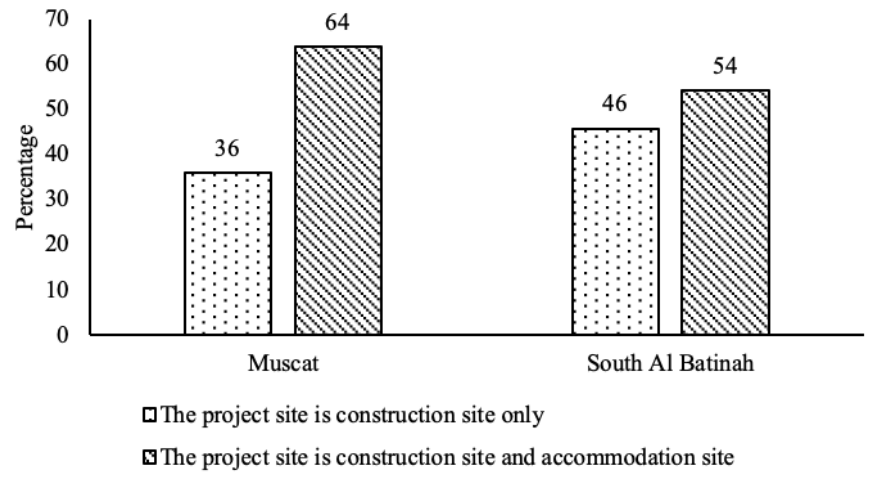

Figure 5: The Distribution of the studied construction companies in terms of the nature of the project site whether it is a construction site only or it is both a construction and an accommodation site at the same time.

Figure 6 shows the level of compliance of the small and medium construction companies towards providing suitable Personal Protective Equipment (PPE) to their construction workers. The results show that a satisfactory level of compliance is maintained by small and medium construction companies in both locations. All companies showed consistent results in both locations regarding safety shoes, head protection, and eye protection. This result is expected since the perception of the OHS in the local market, more specifically, in the small and medium construction companies is all about providing safety shoes, 
head protection, and coverall.

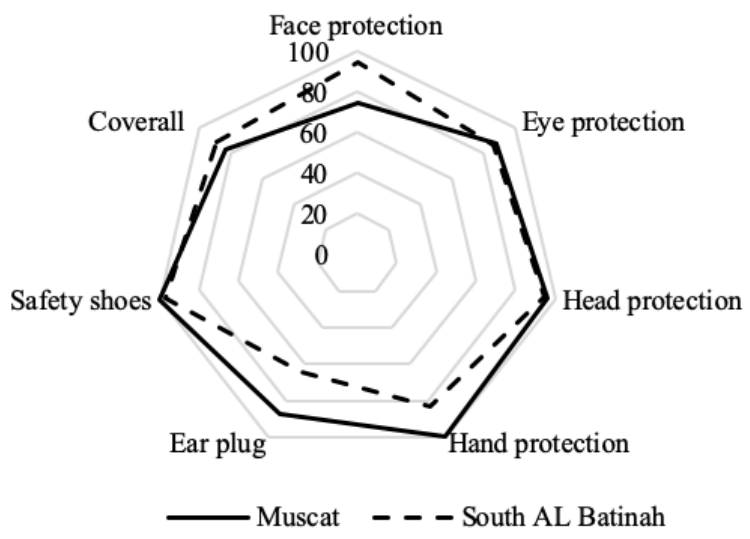

Figure 6: Levels of Compliances of the Studied Construction Companies for Providing Personal Protective Equipment (PPE)

\section{CONCLUSION}

The level of compliance to the Occupational Health and Safety of small and medium construction companies in two governorates, Muscat and South Al Batinah, in Oman were investigated. The study is conducted in three stages, (1) identifying the level of compliance of the small and medium construction companies to the OHS regulatory framework, (2) comprehensively identifying the causation of the non-compliance and the risk generated, and (3) proposing a framework for "Paving Zero Accident Vision" in Oman, and the partial preliminary results of the first stage was discussed and presented. It was found that not all construction companies surrounding their construction sites with fences resulting are posing hazards not only to the construction workers, but the neighborhood hosting the construction site is also affected.

Furthermore, it was found, the majority of the construction sites are also used as accommodation sites for the construction workers. Thus, raising a question over how these companies are maintaining the health-friendly workplace. The small and medium construction companies were able to maintain a satisfactory level of compliance to provide Personal Protective Equipment to their workers which is a good indication about the awareness regarding the importance of providing a safe working environment to the construction companies. This study pinpointed some negative facts about the OHS practices and bridged the way to the second stage of this research which is to identify the root causation of the non-compliance to the OHS regulatory framework and the risk generated.

The limitations of this research are related to the adequate and representative sample size. The study targets, 269 samples, considering 90\% confidence level, and 5\% margin of error of a total of 37289 SMEs. In addition, the awareness and the understanding of the respondents about the OHS regulatory framework is challenging and it requires a substantial time to discuss it. 


\section{REFERENCES}

Arewa, A. \& Farrell, P. (2012). A review of compliance with health and safety regulations and economic performance in small and medium construction enterprises. Edinburgh, UK, s.n., pp. 423-432.

Cagno, E., Micheli, G. J., Masi, D. \& Jacinto, C. (2013). Economic evaluation of OSH and its way to SMEs: A constructive review. Safety Science, Volume 53, pp. 134-152.

Chileshe, N. \& Dzisi, E. (2012). Benefits and barriers of construction health and safety management (HSM): perceptions of practitioners within design organisations. Journal of Engineering Design and Technology, 10(2), pp. 276-298.

Gunduz, M. \& Laitinen, H. (2017). A 10-step safety management framework for construction small and medium-sized enterprises. International Journal of Occupational Safety and Ergonomics, 23(3), p. 353-359.

Hasle, P., Kines, P. \& Anderson, L. P. (2009). Small enterprise owners' accident causation attribution and prevention. Safety Science, pp. 9-19.

He, C., McCabe, B., Jia, G. \& Sun, J. (2020). Effects of Safety Climate and Safety Behavior on Safety Outcomes between Supervisors and Construction Workers. Journal of Construction Engineering and Management, 146(1).

Ikpe, E., Hammon, F. \& Oloke, D. (2012). Cost-Benefit Analysis for Accident Prevention in Construction Projects. Journal of Construction Engineering and Management, 138(8), pp. 991-998.

Ithraa (2015). Setting up a new Business in Oman. [Online] Available at: https://ithraa.om/ar/ Invest-in-Oman/Set-up-a-company.

Kheni, N. A., Gibb, A. G. F. \& Dainty, A. R. J. (2010). Health and Safety Management within Small- and Medium-Sized Enterprises (SMEs) in Developing Countries: Study of Contextual Influences. Journal of Construction Engineering and Management, 10(136), pp. 1104-1115.

LaDou, J. (2003). International Occupational Health. International Journal of Hygiene and Environmental Health, Volume 206, pp. 303-313.

Lai, D., Liu, M. \& Ling, F. (2011). A comparative study on adopting human resource practices for safety management on construction projects in the United States and Singapore. International Journal of Project Management, 29(8), pp. 1018-1032.

Lai, D., Liu, M. \& Ling, F. (2011). A comparative study on adopting human resource practices for safety management on construction projects in the United States and Singapore. International Journal of Project Management, 29(8), p. 1018-1032.

Legg, S. J., Olsen, K. B., Laired, I. S. \& Hasle, P. (2015). Managing safety in small and medium enterprises. Safety Science, Volume 71, pp. 189-196.

Ministry of Manpower (2008). Occupational safety and health, Oman: Ministry of Manpower.

Muscat Daily (2015). Allegations arise that many construction sites in Muscat are giving safety a miss. Muscat: Muscat Daily.

National Survey Authority, Ministry of Defence, (2019). Oman Map. [Online] Available at: http://www.nsaom.org.om/?inc=downloads/maps.

Sunindijo, R. \& Zou, P. (2013). Conceptualizing safety management in construction projects. Journal of Construction Engineering Management, 139(9), p. 1144-1153.

Unnikrishnan, S., Iqbal, R., Singh, A. \& Nimkar, I. (2015). Safety management practices in small 
and medium enterprises in India. Safety and Health Work, 6(1), p. 46-55.

Zhou, Z., Goh, Y. \& Li, Q. (2015). Overview and analysis of safety management studies in the construction industry. Safety Science, Volume 72, p. 337-350.

Zhou, Z., Irizarry, J. \& Li, Q. (2013). Applying advanced technology to improve safety management in the construction industry: a literature review. Construction Management and Economics, 31(6), p. 606-622. 